\title{
A comparative study of intravenous hydralazine versus labetalol in the management of severe hypertension in pregnancy
}

\author{
Shruti Singh, Swati Kochar, Santosh Khajotia, Suman Budania, Anjana \\ Correspondence: Dr. Shruti Singh, Post Graduate Student, Department of Obstetrics and \\ Gynaecology, PBM Hospital, Rajasthan University of Health Sciences, Bikaner, Rajasthan, \\ India; Email:shruti.118.ss@gmail.com
}

Distributed under Creative Commons Attribution-Share Alike 4.0 International.

\begin{abstract}
Objective: The objective of this study is to compare the efficacy as well as safety profile of hydralazine and labetalol in severe hypertension of pregnancy. Methodology: Hundred (100) women with severe pregnancy induced hypertension were randomly allocated into two groups of 50 each. Study group was given intravenous hydralazine and control group was treated with labetalol. The efficacy of two drugs were noted in terms of time taken to achieve target blood pressure, number of doses required and number of patients developing severe persistent hypertension. Results: The average time taken to control blood pressure (BP) in hydralazine group was $32.66 \pm 18.79$ minutes and $30.70 \pm 20.46$ minutes in labetalol group and this was statistically significant $(\mathrm{p}<0.001)$.There was no statistical difference between the two drugs in terms of efficacy, perinatal outcome and adverse affect except headache which was significantly more in hydralazine group. Conclusion: Both hydralazine and labetalol can be used to treat hypertensive emergencies.
\end{abstract}

Keywords: Hydralazine, labetalol, severe hypertension in pregnancy, headache, sudden hypotension.

Hypertensive disorders of pregnancy are one of the most common medical complications. It affects 10 $15 \%$ of all pregnancy and a major cause of maternal, fetal and neonatal morbidity and mortality. ${ }^{1,2}$ Around the world this group of disorders comprise one of the four leading causes of maternal death. According to National High Blood Pressure Education Programme (NHBPEP) working group and American college of obstetricians and gynaecologists (ACOG) hypertension in pregnancy is defined as diastolic blood pressure $>90$ $\mathrm{mm}$ of $\mathrm{Hg}$ or systolic blood pressure $>140 \mathrm{~mm}$ of $\mathrm{Hg}$ after 20 wks of gestation in women with previously normal blood pressure. ${ }^{3,4}$

Pre-eclampsia is a syndrome which may also be associated with myriad signs and symptoms such as edema, visual disturbance, headache and epigastric pain. It is also associated with laboratory abnormalities like elevated liver enzymes and low platelet count

Received: $5^{\text {th }}$ March 2017. Accepted: $5^{\text {th }}$ May 2017.

Singh S, Kochar S, Khajotia S, Budania S, Anjana. A comparative study of intravenous hydralazine versus labetalol in the management of severe hypertension in pregnancy. The New Indian Journal of OBGYN. 2017; 4(1):22-6 
(HELLP syndrome). There is a consensus that due to their risk the patient should be treated with anti hypertensive agent to achieve rapid control of hypertension.

Hydralazine and labetalol are two most commonly used antihypertensive agents used for hypertensive crisis. Hydralazine is a direct acting smooth muscle relaxant acting as a vasodilator primarily in arteries and arterioles. Labetalol is an $\alpha$ and non selective $\beta$ blocker. It decreases blood pressure by decreasing systemic vascular resistance. The purpose of this study is to evaluate intravenous hydralazine versus intravenous labetalol regimens in terms of their speed, efficacy and tolerability in the acute control of blood pressure in severe hypertension of pregnancy.

\section{Materials and method}

A randomized controlled trial was conducted in the Department of Obstetrics and Gynaecology from February 2016 to December 2016 at PBM Hospital, Bikaner comparing hydralazine to labetalol in the management of severe hypertension. For the sample size calculation a rate of persistent severe hypertension of $3.8 \%$ in the hydralazine group and $13.5 \%$ in the labetalol group $\alpha$ error rate of $5 \%$ and a power of $80 \%$ calculated sample size was 100 .

The pregnant women were randomized into two groups using computer generated table randomly either intravenous hydralazine or intravenous labetalol. In study population, women with $>28$ weeks pregnancy were taken and divided in two groups on basis of computer generated table. Proper informed written consent was obtained from both groups. Patients were eligible for inclusion if they were 18-35 years old, >28 weeks gestation, singleton pregnancy, hemodynamically stable and BP >160/110 mmHg. Patients with essential hypertension, cardiac disease, bronchial asthma, hematological disorder, sensitive to labetalol or hydralazine, thyrotoxicosis, liver disorders, multifetal gestations and hemodynamic instability were excluded.

Group A - treated with Hydralazine (50 cases); Group B - treated with Labetalol (50 cases).
Patients randomized to the hydralazine group were administered $5 \mathrm{mg}$ of intravenous hydralazine. Blood pressure was checked every 15 minutes. The dose was repeated every 15 minutes until the target blood pressure that is SBP $<160 \mathrm{mmHg}$ and $\mathrm{DBP}<110 \mathrm{mmHg}$ was achieved. The dose was limited to maximum of 4 doses. Patients in the control group were administered with $20 \mathrm{mg}(4 \mathrm{ml})$ of labetalol. Blood pressure was measured every 15 minutes. The second dose of $40 \mathrm{mg}$ $(80 \mathrm{ml})$ labetalol was given if the target BP was not achieved within 15 minutes. If blood pressure was not controlled another $80 \mathrm{mg}$ was infused, this was repeated at 15 minutes interval for maximum total dose of $220 \mathrm{mg}$. Inj. labetalol was infused at a slow rate over 2-5 minutes. The time required for BP control to target value was noted. The number of doses required to achieve target BP was noted. Adverse effects like maternal hypotension, tachycardia, and nausea were noted. Data obtained was analysed statistically. Chi square test, student $\mathrm{t}$-test and fischer exact test were used to analyse the data. Probability value $<0.05$ were considered significant. Quantitative variables have been indicated in mean \pm SD.

\section{Results}

A total of 100 women meeting the inclusion criteria were included in the study. The baseline variables were

Table 1: Baseline variables of patients

\begin{tabular}{lll}
\hline Variables & Group A & Group B \\
\hline $\begin{array}{l}\text { Age in years } \\
\text { Gestational age in }\end{array}$ & $24.8 \pm 3.80$ & $24.64 \pm 3.79$ \\
$\begin{array}{l}\text { weeks } \\
\text { Booking status } \\
\text { (Booked) in \% }\end{array}$ & 68 & $35.66 \pm 1.73$ \\
$\begin{array}{l}\text { Gravidity } \\
\text { (Gravida 1) in \% }\end{array}$ & 64 & 44 \\
\hline
\end{tabular}

similar in both arms of study (table 1). In the study group the mean time required to achieve target BP was $32.66 \pm 18.79$ minutes while in the control group it was $30.70 \pm 20.46$ minutes. This difference was found to be significant due to faster onset of action of labetalol. 
Table 2: Baseline variables, dose and time required to achieve target $B P$

\begin{tabular}{llll}
\hline Variables & Group A & Group B & P value \\
\hline Initial systolic BP $(\mathrm{mm} \mathrm{Hg})$ & $168.12 \pm 12.06$ & $168.88 \pm 12.33$ & 0.378 \\
Initial diastolic BP(mm Hg) & $110.60 \pm 6.80$ & $112.68 \pm 10.12$ & 0.214 \\
Final systolic BP(mm Hg) & $146.16 \pm 9.27$ & $146.52 \pm 10.12$ & 0.327 \\
Final diastolic BP(mm Hg) & $92.6 \pm 5.01$ & $94.96 \pm 9.96$ & 0.011 \\
$\begin{array}{l}\text { Duration needed to control } \\
\text { BP in minutes }\end{array}$ & $32.6 \pm 8.79$ & $30.70 \pm 20.46$ & $<0.001$ \\
Doses given to control BP & $1.7 \pm 0.64$ & $1.80 \pm 0.81$ & 0.865 \\
\hline
\end{tabular}

In the hydralazine group 24 patients and 21 patients in labetalol group achieved target blood pressure after single dose. In both groups 19 patients achieved target BP after 2 doses and this difference was not significant. Thus there was no difference between the two drugs with respect to the number of doses required to achieve the target blood pressure. There were 2 treatment failures in hydralazine and 3 in labetalol group (table 2).

Table 3: Distribution of cases according to Maternal and Fetal outcome

\begin{tabular}{lll}
\hline Variables & $\begin{array}{l}\text { Group A } \\
\text { Number }\end{array}$ & $\begin{array}{l}\text { Group B } \\
\text { Number }\end{array}$ \\
\hline Maternal complications & & \\
Headache & 7 & 1 \\
Nausea & 1 & 2 \\
Vomiting & 0 & 2 \\
Eclampsia & 1 & 0 \\
Modes of delivery & & \\
Vaginal delivery & 40 & 41 \\
LSCS & 10 & 9 \\
Fetal outcome & & \\
NICU admission & 34 & 33 \\
VLBW (1.0-1.5Kg) & 3 & 2 \\
LBW (1.6-2.5Kg) & 18 & 13 \\
Normal BW (2.6-3.9Kg) & 29 & 35 \\
\hline
\end{tabular}

The perinatal outcome in two groups were analysed on the basis of live or still birth, NICU admission and birth weight. The difference was not statistically significant.

The adverse effects of the two drugs are comparable and there was no statistical difference between the two drugs. Headache was significantly more in hydralazine group (table 3).

\section{Discussion}

This study demonstrates that both the drugs remain as effective antihypertensive agents in hypertensive emergencies as severe preeclampsia. This finding correlate earlier studies including cochrane review on the efficacy of both drugs in hypertensive crisis in pregnancy ${ }^{5-7}$.

The average time taken to achieve desired BP control in hydralazine group was $32.66 \pm 18.79$ minutes and $30.70 \pm 20.46$ minutes in labetalol group and this was statistically significant $(\mathrm{p}<0.001)$. This was contrary to other studies where time taken to achieve desired BP control was similar for both groups. This may be due to faster onset of action of labetalol compared to hydralazine. In the present study target BP was achieved after single dose in $24(48 \%)$ patients in hydralazine group and $21(42 \%)$ in the labetalol group. In both groups 19 patients achieved target BP after 2 doses and this difference was not significant. This finding perhaps forms the basis of accepting the null hypothesis in this study that demonstrated no superiority of one over the other in achieving fast blood pressure control. In our study it was seen that 2 patients in hydralazine group and 3 patients in labetalol group has severe persistent hypertension ( $\mathrm{p}$ value $=0.646$ ) which was statistically insignificant. There were no significant adverse events attributed to either drugs in terms of adverse effects like maternal tachycardia (0:1), nausea (1:2), vomiting (0:2).There was no maternal hypotension in both groups. Similar safety profile and findings were seen in studies of Pasquale $^{8}$ and Nombur ${ }^{9}$. However headache was significantly more frequent in patients given hydralazine as compared to labetalol group [7 (14\%) patients in hydralazine group had headache compared to $1(2 \%)$ patients in labetalol group]. This difference was statistically significant. This may be due to dilatation of capacitance vessels in the cerebral circulation resulting in severe headache.

There was no significant difference in fetal outcome in both groups where 47 (94\%) patient in hydralazine 
and $49(98 \%)$ patients in labetalol group had live fetal outcome ( $\mathrm{p}$ value $=0.307$ ) further collaborating the finding of non superiority of these drugs over one another. The patients who did not have live fetal outcome were the patients who had documented IUD before commencement of treatment in hydralazine and labetalol groups. These deaths were more likely to be the complication from uteroplacental insufficiency or abruption placentae than from the effect of either hydralazine or labetalol group. Sixty eight percent $(68 \%)$ babies in hydralazine group required NICU admission and $66 \%$ babies in labetalol group required the same. These were mainly pre term or LBW or were kept in observation for few hours. This was non significant similar to the findings of Nombur ${ }^{9}$ and Deka Nabanita ${ }^{10}$. The recorded VLBW and LBW were not statistically different between both groups. In a meta analysis conducted by Duley et al ${ }^{6}$ they found insufficient data for reliable conclusions about the comparative effects of these two antihypertensive drugs. They concluded that until better evidence is available, the choice of antihypertensive should depend on what is known about adverse drug effects and how familiar the clinician is with a particular drug. Our findings in this study may add to the existing knowledge on this subject matter. However larger trials of community based study on severe hypertension in pregnancy are needed to confirm these findings.

\section{Conclusion}

Thus labetalol and hydralazine were found to be equally effective in terms of number of doses required to achieve the target blood pressure. Mean time duration to achieve the target blood pressure was slightly lower for labetalol than hydralazine due to faster onset of action of labetalol. Apart from headache there was no significant difference between the two drugs in terms of adverse effects like maternal tachycardia, nausea, vomiting. Headache was significantly more in hydralazine group compared to labetalol. The two drugs were similar when perinatal outcome, NICU admission were compared.

To conclude, choice of antihypertensive should depend on the clinicians experience, familiarity, drug availability and cost of the drugs. This study has shown that hydralazine and labetalol fulfill the criteria required for an antihypertensive drug to treat severe hypertension in pregnancy with adequate efficacy and safety.

Conflict of interest: None. Disclaimer: Nil.

\section{References}

1)Lori JR, Starke AE. A critical analysis of maternal morbidity and mortality in Liberia,West Africa. Midwifery. 2012; 28(1): 67-72.

2)Moraes AP, Barreto SM, Passos VM, Golino PS, Costa JA, Vasconcelos MX. Incidence and main causes of severe maternal morbidity in São Luis, Maranhão, Brazil: a longitudinal study. Sao Paulo Med J. 2011; 129(3): 14652.

3)NHBPEP Working Group on High Blood Pressure. Report of NHBPEP Working group in Hypertension in Pregnancy. Am J ObstetGynecol. 2000; 183: S1-22.

4)ACOG Practice bulletin No.33. Diagnosis and management of preeclampsia and eclampsia. Am J Obstet Gynecol. 2002; 99(1): 159-67.

5)Vigil-De Gracia P, Lasso M, Ruiz E, Vega-Malek JC, de Mena FT, López JC. Severe hypertension in pregnancy: hydralazine or labetalol - A randomized clinical trial. Eur J Obstet Gynecol Reprod Biol. 2006; 128(1-2):157-62.

6)Duley L, Henderson-Smart DJ. Drugs for rapid treatment of very high blood pressure during pregnancy. Cochrane Database Syst Rev. 2003; 2.

7)Mabie WC, Gonzalez AR, Sibai BM, Amon E. A comparative trial of labetalol and hydralazine in the acute management of severe hypertension complicating pregnancy. Obstet Gynecol. 1987; 70(3 Pt 1): 328-33.

8)Delgado De Pasquale S, Velarde R, Reyes O, De La Ossa K. Hydralazine vs labetalol for the treatment of severe hypertensive disorders of pregnancy. A randomized controlled trial. Pregnancy Hypertens. 2014; 4(1): 19-22.

9)Nombur LI, Agida ET, Yabajilsah A, Ekele BA. A comparison of Hydralazine and Labetalol in the management of severe Preeclampsia. J Women's Health Care. 2014; 3: 6. 
10)Deka N, Das GC, Baishya S, Yadav S. A comparative study of hydralazine versus labetalol in the management of pregnancy induced hypertension (PIH). Sch J App Med Sci. 2016; 4(11B): 3996-99.

\section{Shruti Singh ${ }^{1}$, Swati Kochar ${ }^{2}$, Santosh Khajotia ${ }^{3}$,} Suman Budania ${ }^{4}$, Anjana ${ }^{5}$

${ }^{1}$ Post Graduate Student, Department of Obstetrics and Gynaecology, PBM Hospital,

Rajasthan University of Health Sciences, Bikaner, Rajasthan, India; ${ }^{2}$ Associate Professor, Department of Obstetrics and Gynaecology, PBM
Hospital, Rajasthan University of Health Sciences, Bikaner, Rajasthan, India; ${ }^{3}$ Professor, Department of Obstetrics and Gynaecology, PBM Hospital, Rajasthan University of Health Sciences, Bikaner, Rajasthan, India; ${ }^{4}$ Assistant Professor, Department of Obstetrics and Gynaecology, PBM Hospital, Rajasthan University of Health Sciences, Bikaner, Rajasthan, India; ${ }^{5}$ Post Graduate Student, Department of Obstetrics and Gynaecology, PBM Hospital, Rajasthan University of Health Sciences, Bikaner, Rajasthan, India. 